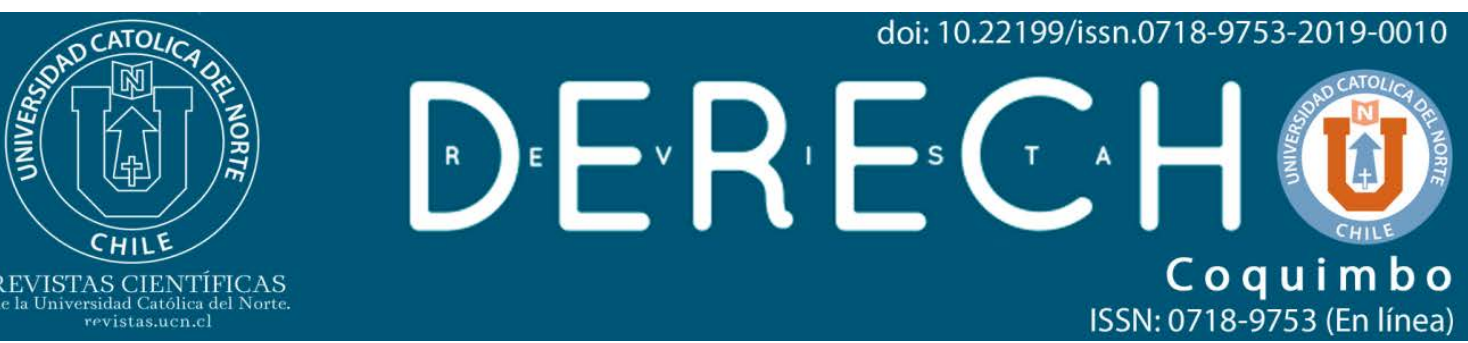

\title{
Delimitación de las esferas jurisdiccionales entre los tribu- nales ordinarios y el tribunal constitucional
}

\section{Delimitation of jurisdictional spheres between ordinary courts and the constitutional court}

\author{
Kamel Cazor Aliste* (D) https://orcid.org/ 0000-0003-0935-8052 \\ Rodrigo Pica Flores** (Dttps://orcid.org/0000-0003-4528-808X \\ *Universidad Católica del Norte, Coquimbo, Chile. Profesor. Doctor en Derecho, U. de Valladolid. \\ @azor@ucn.cl \\ **Universidad de Chile, Santiago, Chile. Profesor. Magíster en Derecho Constitucional, U. de Talca. \\ ? rodrigopica@hotmail.com
}

(cc) BY

\section{Resumen:}

Se aborda la cuestión de la delimitación de las esferas jurisdiccionales entre los Tribunales Ordinarios y el Tribunal Constitucional en Chile, que no está explícita en el ordenamiento jurídico para los efectos de la acción de inaplicabilidad. La búsqueda de tal demarcación es un problema en torno al órgano jurisdiccional que le correspondería determinarla y la consecuente rearticulación entre las jurisdicciones implicadas. El objetivo principal de la indagación, en consecuencia, estudia los criterios teóricos y jurisprudenciales de delimitación de las esferas competenciales entre los Tribunales Ordinarios y la Jurisdicción Constitucional, en el marco de la aplicación de la Constitución al resolver una asunto en concreto un juez ordinario y su vinculación con la acción de inaplicabilidad por parte del Tribunal Constitucional.

Palabras Clave: Tribunal constitucional; Jurisdicción ordinaria; Acción de inaplicabilidad.

\begin{abstract}
:
The delimitation of the jurisdictional spheres between the Ordinary Courts and the Constitutional Court in Chile, which is not explicit in the legal order regarding the writ of nonapplicability. The search for such a demarcation is a problem around the jurisdictional body that would be responsible for determining it and the consequent rearticulation between the jurisdictions involved. The main goal of this research paper, therefore, is to study the theoretical and jurisprudential criteria of delimitation of the competence areas between the Ordinary Courts and the Constitutional Jurisdiction, within the framework of the application of the Constitution when an ordinary judge adjudicate a concrete issue and its relation with the writ of non-applicability by the Constitutional Court.

Keywords: Constitutional court; Ordinary jurisdiction; Writ of non-applicability.
\end{abstract}




\section{Introducción: el problema de la delimitación de las esferas jurisdic- cionales}

La delimitación de las esferas jurisdiccionales entre los Tribunales Ordinarios y el Tribunal Constitucional, no está explícita en el ordenamiento jurídico chileno para los efectos de la acción de inaplicabilidad (Constitución Política de la República de Chile, 1980, art. 93, n० 6 , inc 11) 1), por lo que su búsqueda es un problema en torno al órgano jurisdiccional que le correspondería determinarla y la consecuente rearticulación entre las jurisdicciones implicadas. El objetivo general de este trabajo será, en consecuencia, estudiar los criterios teóricos y jurisprudenciales de delimitación de las esferas jurisdiccionales entre los Tribunales Ordinarios y el Tribunal Constitucional, en el marco de la aplicación de la Constitución al resolver un asunto en concreto el juez ordinario.

A su vez, dentro de los objetivos específicos -que no necesariamente se abordarán en profundidad, debido a los límites propios de este tipo de trabajo- se podrían destacar, entre otros, los siguientes: analizar el rol de los órganos jurisdiccionales en el control de constitucionalidad de los preceptos legales, dentro del contexto de un sistema de jurisdicción concentrado y desde una perspectiva comparada, para precisar de qué modo ha sido afrontada esta problemática en otros ordenamientos; abordar lo concerniente al alcance de la verificación que lleva a cabo el Tribunal Constitucional, vía acción de inaplicabilidad, cuando se refiere a un vicio de orden procesal y la posibilidad de revisar la tramitación del juicio o gestión pendiente a fin de precisar la concurrencia del "efecto contrario a la Constitución"; revisar las complejidades de diferenciación y contacto en la relación entre las acciones de inaplicabilidad y protección, especialmente la anomalía del "amparo imperfecto" que generan las sentencias estimatorias de inaplicabilidad en las gestiones pendientes; $y$, en fin, estudiar el denominado juicio incidental de constitucionalidad que pueden iniciar los jueces ordinarios a través de una acción de inaplicabilidad.

Ahora bien, dado que el sistema de jurisdicción constitucional en Chile, presentaba, antes de la reforma constitucional de 2005, la particularidad de ser receptáculo directo -o indirecto- de la influencia tanto de la jurisdicción difusa como concentrada,

\footnotetext{
1 "Son atribuciones del Tribunal Constitucional: № $6^{\circ}$ Resolver, por la mayoría de sus miembros en ejercicio, la inaplicabilidad de un precepto legal cuya aplicación en cualquier gestión que se siga ante un tribunal ordinario o especial, resulte contraria a la Constitución (...) Inciso 110: En el caso del número 60, la cuestión podrá ser planteada por cualquiera de las partes o por el juez que conoce del asunto. Corresponderá a cualquiera de las salas del Tribunal declarar, sin ulterior recurso, la admisibilidad de la cuestión siempre que verifique la existencia de una gestión pendiente ante el tribunal ordinario o especial, que la aplicación del precepto legal impugnado pueda resultar decisivo en la resolución de un asunto, que la impugnación esté fundada razonablemente y se cumplan los demás requisitos que establezca la ley. A esta misma sala le corresponderá resolver la suspensión del procedimiento en que se ha originado la acción de inaplicabilidad por inconstitucionalidad".
} 
interesaba resaltar de él, en su momento, que las adaptaciones que sufrió en la aplicación de dichos modelos, se traducía en que, por una lado, no se trataba del sistema norteamericano originario de la judicial review, ni tampoco, por el otro, del sistema kelseniano puro de justicia constitucional abstracta, sino de sistemas adaptados a la realidad jurídica chilena. En definitiva, era posible concluir "que el sistema de jurisdicción constitucional chileno, no obstante la innegable influencia del Derecho comparado, fue más bien el resultado de su propia experiencia jurídica (...) Sin embargo, el sistema presentaba claros vacíos y deficiencias; pues, la existencia de un doble mecanismo jurisdiccional de control de constitucionalidad, como órganos autónomos uno del otro, generaba, en ciertos casos, una dispersión y anarquización en el control, estableciéndose, por ende, dos parámetros o criterios diferentes en la valoración de la Constitución, como asimismo, problemas competenciales entre ambos órganos verificadores" (Cazor Aliste, 2001, pp. 98-99).

Después de la reforma de 2005, en la cual se asume -o se pretende asumir- el sistema concentrado (en donde el Tribunal Constitucional posee la competencia exclusiva en el control de constitucionalidad de la ley), se plantea nuevamente la cuestión de delimitar las esferas jurisdiccionales entre los Tribunales Ordinarios y el Tribunal Constitucional, que, como se verá, no está explícita en el ordenamiento jurídico para los efectos de la acción de inaplicabilidad (la que, como bien es sabido, fue traspasada desde la competencia de la Corte Suprema al Tribunal Constitucional). Por lo que la búsqueda de tal delimitación, es un problema en torno al órgano jurisdiccional que le correspondería determinarla y la consecuente rearticulación entre las jurisdicciones implicadas, especialmente teniendo en cuenta el sistema concentrado de control de constitucionalidad que se pretende asumir y, en definitiva, consolidar.

Todo lo cual ha generado un claro tejido de problematización de un alto interés de estudio, que hará frente a una temática esencial en la esfera de la jurisdicción constitucional chilena, y que comprenden no solo aspectos teóricos sino también de la práctica jurisprudencial. En este contexto, al abordar la delimitación de las esferas jurisdiccionales entre los Tribunales Ordinarios y el Tribunal Constitucional, en el marco de la aplicación de la Constitución, significa abordar un asunto en sí complejo y nebuloso, que pone en evidencia la naturaleza conflictiva de las relaciones entre dichas jurisdicciones.

En efecto, aproximarse a la acción de inaplicabilidad desde esta perspectiva, justifica, por sí misma, su relevancia como objeto de estudio, ya que pretende, a lo menos preliminarmente, describir el rol de los jueces ordinarios aplicando la Constitución en la resolución de un conflicto de legalidad; y permitirá, a su vez, al Tribunal Constitucional precisar el reconocimiento de los conflictos a los cuales dedicará sentencias definitivas, lo que sin duda implicará una redefinición del espacio jurisdiccional de este Tribunal en la esfera de la inaplicabilidad. 
Delimitación de las esferas jurisdiccionales entre los tribunales ordinarios y el tribunal...

Analizar a la acción de inaplicabilidad desde este enfoque, claramente es un problema actual en la esfera de la jurisdicción constitucional chilena, con una fuerte incidencia en el funcionamiento de nuestro Estado constitucional de Derecho. Sobre el particular, conviene citar las palabras de Francisco Tomás y Valiente: "Separación orgánica, articulación competencial y supremacía formal y funcional del Tribunal Constitucional son los tres principios que deben orientar la interrelación entre jurisdicción ordinaria y jurisdicción constitucional. De ellos -prosigue- hemos de servirnos para dibujar líneas fronterizas, para poner claridad en zonas oscuras y para perfilar conceptos técnicos cada vez más precisos en un lenguaje común a todos los juristas" (Tomás y Valiente, 1993, p. 81).

Respecto a las conclusiones del trabajo, se busca esencialmente describir la línea que delimita el control concentrado de inaplicabilidad, con las potestades de los jueces ordinarios para aplicar e interpretar la ley de conformidad con la Constitución. También se persigue reconocer la existencia de un conflicto de constitucionalidad real y no aparente de parte del juez ordinario al momento de requerir de inaplicabilidad, y en qué medida el conflicto aparente hace emerger las potestades de interpretación conforme de dicho juez ordinario. Todo lo cual, igualmente, ayudará a despejar las posibilidades que poseen de los jueces ordinarios para ejercitar, dentro del contexto de la inaplicabilidad, el denominado juicio incidental de constitucionalidad.

\section{Marco teórico derecho comparado}

Cabe recordar -como es coincidente la dogmática clásica en la materia- que "la jurisdicción constitucional es heredera de una tradición americana-europea integrada por distintas líneas de evolución, de influencia recíproca (...) Condición esencial de la jurisdicción constitucional, cuyo tratamiento por la historia de las ideas se remonta por bastante en el tiempo, es el explícito o implícito reconocimiento de la existencia de normas de superior jerarquía o, en términos más modernos, de una 'supremacía de la Constitución"' (Weber, 1986, p. 48). De ahí que, para el profesor Fix Zamudio, estas dos tendencias (es decir, las que se han calificado como "americana" y "austriaca" del control de la constitucionalidad de los actos de autoridad, tomando en consideración que tuvieron su nacimiento en América -no sólo los Estados Unidos, sino en la mayor parte de Latinoamérica, siguiendo el ejemplo norteamericano- y en Austria, respectivamente), se disputaron la primacía en los años siguientes a la Primera Guerra Mundial, y aun cuando en un principio parecía triunfante la tendencia angloamericana, después de la tremenda experiencia de las dictaduras nazifascistas y de la Segunda Guerra Mundial, la balanza se ha inclinado por los tribunales constitucionales especializados (Cazor Aliste, 2001, p. 92).

En este contexto, la doctrina de la época reafirmaba que "no bastaba declarar que la Constitución fuera la Ley suprema, para que se lograra su respeto; sino que era 
indispensable que los Estados que aceptaban la superlegalidad constitucional organizaran cuidadosamente el conjunto de medios destinados a asegurar en la práctica la superioridad de las leyes constitucionales sobre las ordinarias" (Aguilar y Maya, 1945, p. 5). Sin embargo, al vincularlo con la configuración de la jurisdicción constitucional, el problema es más hondo y su solución también. Toda vez que, como bien es sabido, "su más profundo cimiento consiste en pronunciarse acerca de si la primacía de la Constitución es admisible y en si, admitida, de ahí se deriva la declaración de anulación de las leyes inconstitucionales" (Tomás y Valiente, 1993, p. 89). Cabe recordar asimismo que, en última instancia, "lo decisivo no es tanto el método de garantía de la supremacía de la Constitución como la aceptación de su superioridad frente a cualquier ley ordinaria. De ahí que Kelsen -se indica- viera en las críticas contra la justicia constitucional tan sólo un modo de disimular el deseo del poder político que se expresa en el órgano legislativo de no dejarse limitar por las normas contenidas en la Constitución (...) Por lo mismo también la más profunda objeción de Carl Schmitt frente a la justicia constitucional concentrada consiste en negar el sistema de jerarquía de normas y la supremacía de la Constitución (...) Si se acepta este planteamiento ciertamente la jurisdicción constitucional carece de sentido (...) La crítica de Carl Schmitt sitúa el problema en el terreno legislativo ordinario, que es el 'locus' natural de las decisiones políticas, no en el ámbito de un poder constituyente (...) Si no hay jerarquía jurídica normativa, todo es política y el intento de control jurídico de la constitucionalidad de las normas, lejos de constituir la judicialización de la política, sólo sería una bastarda politización de la justicia (...) Hay que optar, pues, a favor o en contra de la supremacía de la Constitución como norma suprema, aun sabiendo que esa elección no elimina por sí misma los riesgos de la jurisdicción constitucional" (Tomás y Valiente, 1993, p. 90 y 91).

Según la literatura general en esta temática, dentro de los sistemas de jurisdicción constitucional existentes se destacan principalmente dos bloques: los sistemas de jurisdicción difusa y los sistemas de jurisdicción concentrada. El primero se inspira en la experiencia norteamericana, y el segundo en la tradición austriaco-kelseniana ${ }^{2}$. Sin embargo, cabe destacar que cierto sector de la doctrina chilena es contraria a la utilización de la dicotomía "difuso" o "concentrado" (la que algunos califican de "ruinosa"), pues se pretendería utilizar estos opuestos teóricos, para explicar una múltiple variedad de instituciones, que a su juicio son muy difíciles de clasificar (Ruiz-Tagle Vial, 1999, p. 82). También se ha hablado de una progresiva fusión de sistemas de control jurisdiccional "difuso" y "concentrado" (Zúñiga Urbina, 2002, pp. 127-129), en donde tales modelos analíticos (difuso-concentrado) han perdido utilidad, "puesto que la organización y procedimientos son elementos técnicos relevantes de la institución jurídica, pero su núcleo esencial es la finalidad" (Zúñiga Urbina, 2002, pp. 127-129). Siguiendo esta línea argumental (idea que más adelante también desarrollaremos), se puede plantear que, más que la dicotomía entre "concentrado" y "difuso", hoy es la diferenciación entre control

\footnotetext{
2 Respecto a la jurisdicción constitucional concentrada europea, es texto de consulta obligada la siguiente obra: Cruz Villalón (1987, p. 474).
}

Rev. derecho (Coquimbo, En línea) 2019, 26: e3589 
Delimitación de las esferas jurisdiccionales entre los tribunales ordinarios y el tribunal...

abstracto y control concreto la conceptualización más habitual, particularmente teniendo en cuenta que la introducción del control concreto en un sistema concentrado de jurisdicción constitucional, es el hecho que genera, en muchos casos, la necesidad de delimitar y articular a dicha jurisdicción con el Poder Judicial. En efecto, cabe recordar que "desde el comienzo del funcionamiento de los tribunales constitucionales europeos la atención fue puesta principalmente en las relaciones entre ellos y el poder legislativo, [y] es básicamente respecto del legislador donde se esperaban las principales tensiones con este nuevo órgano constitucional", es decir, se trataba "de un contraste entre la labor de un legislador democrático 'positivo' contrastada [a su vez] con una actividad de 'legislador negativo' no democrático" (Bordalí Salamanca, 2006, pp. 37-38). Sin embargo, "esta concepción cambió radicalmente desde el momento de la creación de la cuestión de constitucionalidad que pueden promover los jueces ordinarios ante el Tribunal Constitucional; cuestión de constitucionalidad [que] se introdujo en la Constitución austriaca con la reforma de 1929 y [que] luego fue incorporada por la mayoría de los sistemas de justicia constitucional europeos" (Bordalí Salamanca, 2006, p. 39). Así, como también lo explicaremos luego, se admiten, por ejemplo, un control difuso con Tribunal Constitucional (Portugal) y sistemas en que los jueces plantean la cuestión de inconstitucionalidad (Italia).

En este contexto, los tribunales ordinarios europeos comenzaron a analizar la constitucionalidad de las leyes que han de aplicar a decisiones en casos particulares, que luego deberán remitir, vía cuestión de constitucionalidad, al Tribunal Constitucional para su dictamen, no pudiendo, en consecuencia, el juez ordinario declarar por sí mismo la inconstitucionalidad de la ley; asunto que es diferente a la función de los jueces en el modelo de "control difuso" de los Estados Unidos, en donde es este mismo juez ordinario quien realiza la declaración de inaplicabilidad y no de inconstitucionalidad de la ley, correspondiéndole esta última función a la Corte Suprema Federal. Como expresa García de Enterría y Martínez-Carande (1988) : “Frente al llamado 'control difuso' americano, que implica que todos los jueces están habilitados para inaplicar las leyes cuando las juzgan contrarias a la Constitución (multiplicidad de control en el que, sin embargo, pone orden el principio stare decisis, que vincula los Tribunales inferiores a la jurisprudencia de la Supreme Court), el sistema kelseniano configura un 'control concentrado', confiado a un solo Tribunal, el Tribunal Constitucional, único habilitado para declarar la inconstitucionalidad de una ley y al cual deberán dirigirse los tribunales que estén en trance de aplicar dicha ley, los cuales, de este modo, carecen del poder de inaplicar las leyes inconstitucionales por sí mismos"(pp. 56-57).

Además, cabe agregar, en este caso de "control concentrado", que el Tribunal Constitucional, en principio, no enjuicia ningún supuesto de hecho singular, sino sólo el problema puramente abstracto de compatibilidad lógica entre el pronunciamiento, también abstracto, de una ley y la norma (abstracta) de la Constitución. De ahí que se haya concluido lo siguiente: "El rigor lógico con que este principio es mantenido lleva a Kelsen a sostener que hasta tanto el Tribunal Constitucional no ha declarado la Ley inconstitucional (declaración que tiene efectos erga omnes, lo que es propio de un acto legislativo- 
'fuerza de ley'-, aunque aquí sea de abrogación) dicha ley es válida, que es lo que justifica que los jueces y Tribunales ordinarios no puedan inaplicarla; no se da, pues, como en la relación Ley-Reglamento (y como el sistema americano de judicial review aplica en la relación Constitución-Ley), un vicio de nulidad de la ley inconstitucional, sino de mera anulabilidad" (García de Enterría y Martínez-Carande, 1988, p. 57).

De esta forma, en los orígenes del sistema "concentrado", el control de normas aparece totalmente desvinculado de su aplicación a casos específicos, por lo que, hasta mediados del siglo XX, se podía asumir una conceptualización concentrada-abstracta del sistema europeo, al punto que se señalaba, como lugar común, que por parte de los tribunales constitucionales "no se enjuicia hechos concretos" sino sólo "la compatibilidad entre dos normas abstractas" (García de Enterría y Martínez-Carande, 1988, p. 57). En contraposición al carácter difuso-concreto del sistema norteamericano -que nace vinculado indisolublemente a la noción de control concreto-, el sistema concentrado aparece ligado a la noción de control abstracto, en términos que el modelo norteamericano "puede definirse como una forma de control difuso, incidental y declarativo, en tanto que la Verfassungerichtsbarkeit, en su concepción originaria, se presenta como un control concentrado, principal y constitutivo" (Pizzorusso, Volpe, Sorrentino, y Moretti, 1981 , pp. 7 y 24$)$.

No obstante, la total abstracción del modelo concentrado, y su consecuente desvinculación del Poder Judicial, comienza a relativizarse muy tempranamente, pues -como ya se ha dicho- la reforma constitucional austríaca de 1929 confiere iniciativa a los jueces para cuestionar la constitucionalidad de normas ante el Tribunal Constitucional, introduciendo en el sistema concentrado el elemento de "incidentalidad" del control de constitucionalidad norteamericano, que está dado porque "el juicio de constitucionalidad no se instaura autónomamente, sino que surge como un incidente en el curso de un procedimiento jurisdiccional que se realiza ante un juez común" (Rolla, 2005). Tendencia que en la segunda posguerra marcará la introducción del control concreto en el sistema concentrado, y a partir de entonces -como indica la doctrina italiana autorizada- "nos encontramos frente a sistemas que de diverso modo combinan elementos propios del sistema americano con los del sistema austríaco" (Pizzorusso, 2007, p. 118) ${ }^{3}$. Fenómeno que interrelacionará al Tribunal Constitucional y a la Justicia Ordinaria, al permitir el juzgamiento de la aplicación de las normas por los jueces, surgiendo la necesidad de delimitar sus labores (Rubio LLorente, 1997, pp. 441-443).

Un ejemplo claro de tal conclusión, es el caso de Italia, en donde el sistema difuso y el sistema concentrado tienden a confundirse, "puesto que los jueces ordinarios están absolutamente implicados en el control de constitucionalidad de las leyes" (Bordalí Salamanca, 2006, p. 40). Fenómeno que la doctrina italiana popularizó como la guerra fra

\footnotetext{
${ }^{3}$ También ver: Rolla (2005, p. 274).
}

Rev. derecho (Coquimbo, En línea) 2019, 26: e3589 
le due Corti (guerra entre las dos Cortes), que no afecta al contenido del poder de revisión sino a su atribución (Fernández-Fontecha Torres, 2011), esto puede ser interpretado en que los jueces italianos poseen un verdadero monopolio de interpretación constitucional, al determinar si plantean o no la cuestión ante la Corte Constitucional, coexistiendo con el monopolio de dicha Corte que, en definitiva, será la única que declarará la constitucionalidad de la norma. Por ello se ha argumentado que el problema de la existencia de dos jurisdicciones no cuestiona la supremacía de la Constitución, pues la fuerza normativa especial de la misma lo es siempre y vincula a todos los Poderes Públicos por ejemplo, la Constitución Política de la República de Chile (1980, art. 6, inc. $2^{\circ}$ ), así lo indica ${ }^{4}$ ); es decir, el examen de constitucionalidad corresponde tanto a la jurisdicción ordinaria como a la constitucional, por principio y solamente son diferentes las formas de esa aplicación.

Podemos deducir, en consecuencia, que no existe una separación clara entre las jurisdicciones que operan estrictamente en el ámbito de la Constitución y otras exclusivamente en el ámbito de la ley, cuestión que precisamente fue la que generó el problema entre las dos Cortes en Italia (por un lado, la Corte Constitucional y, por el otro, los Tribunales Ordinarios que tienen una Corte de Casación en su cúspide). De ahí que, sea cual sea el modelo de justicia constitucional que se adopte, y exista o no Tribunal Constitucional, todo juez participa en la función de garantía jurisdiccional de la Constitución, y en este sentido todo juez es juez constitucional, porque: "Por un lado, prácticamente no quedan 'modelos puros', de modo que los jueces suelen desempeñar funciones más o menos relevantes que excluyen el absoluto monopolio del Tribunal Constitucional en el rechazo de las normas inconstitucionales (así, a veces los tribunales ordinarios asumen el rechazo de las leyes preconstitucionales o de las normas infralegales). $Y$, por otro lado, aun cuando el Tribunal Constitucional tenga el monopolio del rechazo de leyes inconstitucionales, en muchos sistemas existen vías incidentales de control (como la cuestión de inconstitucionalidad española o la vía similar italiana) en las que el papel de los jueces ordinarios es muy relevante" (Díaz Revorio, 2009, pp.82-84). Igualmente, como ya se ha adelantado, el sistema portugués hace coexistir el control difuso y concentrado mediante un sistema de apelaciones ante al Tribunal Constitucional, en caso de desaplicación de la norma por el juez ordinario (Pegoraro, 2014, p. 57); modelo, este último, de mucha similitud con la acción de inaplicabilidad del ordenamiento chileno.

Finalmente, podemos deducir que la interacción entre la Jurisdicción Ordinaria y el Tribunal Constitucional que se ha narrado del Derecho comparado, también es posible constatarla dentro del actual sistema chileno, especialmente, a propósito de la acción de inaplicabilidad por inconstitucionalidad, en donde claramente -al igual que el sistema comparado- surge la necesidad de delimitar los campos compe-

\footnotetext{
4 "Los preceptos de esta Constitución obligan tanto a los titulares o integrantes de dichos órganos como a toda persona, institución o grupo".
} 
tenciales entre los órganos jurisdiccionales implicados.

\section{Marco teórico derecho nacional}

A fin de abordar los diversos enfoques que ha desarrollado la literatura chilena sobre el tema en estudio, preliminarmente, dos son los interrogantes que es ineludible dilucidar.

a. La primera pregunta que se debe formular es la siguiente: ¿es posible hacer un aporte en este campo investigativo? La respuesta debe ser necesariamente positiva. Pues permitiría, por una parte, distinguir la línea que delimite el control concentrado de inaplicabilidad con las potestades de los jueces ordinarios para aplicar e interpretar la ley de conformidad con la Constitución (arts. $6^{\circ}$ y 76 de la Carta fundamental chilena), y, por otra parte, posibilitaría identificar la existencia de un conflicto de constitucionalidad real -no aparente- de parte del juez ordinario para poder requerir de inaplicabilidad, y en qué medida un conflicto aparente hace emerger las potestades de interpretación conforme de dicho juez de fondo, cuestión directamente vinculada con la delimitación de las esferas jurisdiccionales de los órganos que les toca resolver el asunto. Cuestión que, igualmente, sería clave al momento de ponderar la "fundamentación razonable" de un requerimiento de inaplicabilidad, asunto que, a la luz de la Carta fundamental y la Ley Orgánica del Tribunal Constitucional, es parte del examen de admisibilidad, en el que suelen plantearse peticiones más bien centradas en la "mera legalidad" que en un conflicto de estricta "constitucionalidad". Precisado ello, como resultado, se podría desplegar una línea argumentativa a fin de descifrar qué es lo que puede hacer el juez ordinario, y hasta dónde puede llegar en nombre de la Constitución en su actividad jurisdiccional, determinándose cuándo puede él resolver conforme a la Constitución sin acudir al Tribunal Constitucional, y cuándo se encontrará con sus potestades limitadas, surgiendo consecuencialmente la necesidad de la declaración de inaplicabilidad, recurriendo al Tribunal Constitucional para poder así actuar a nombre de la Constitución.

b. La segunda pregunta que surge también es la siguiente: ¿el problema descrito genera un real impacto en el Derecho chileno? La perspectiva de análisis narrada no ha sido prácticamente abordada ni justificada por la literatura local, pudiendo generarse un importante impacto que se traduce, por un lado, en redefinir el rol de los jueces ordinarios aplicando la Constitución en la resolución de un conflicto de legalidad; $y$, por otro lado, permite precisar el reconocimiento de los conflictos a los cuales dedicara sentencias definitivas el Tribunal Constitucional, lo que sin duda implicará una redefinición de su espacio jurisdiccional en la esfera de la inaplicabilidad. 
Delimitación de las esferas jurisdiccionales entre los tribunales ordinarios y el tribunal...

Como ya se ha mencionado, existe también legitimación activa del juez o tribunal de la causa, asunto que posibilita al tribunal de la gestión pendiente elevar a la verificación del Tribunal Constitucional todo precepto legal, cuya aplicación en ese caso en particular, suscite dudas sobre su constitucionalidad. Es innegable que existen grandes retos frente en esta nueva relación de colaboración entre los Tribunales Ordinarios y el Tribunal Constitucional en Chile, por cuanto supone un rol proactivo de aquéllos en la vigencia del principio de supremacía constitucional. En efecto, si se hace un repaso, en el período 2009-2018, de los casos en que ha operado el juicio incidental de constitucionalidad, solamente se han deducido 92 acciones la inaplicabilidad por el juez o tribunal. Si nos situamos específicamente entre los años 2016-2018, los requerimientos están centrados en las siguientes esferas normativas: a) arts. 102 A a 102 M ley no 19.968: procedimiento contravencional y arts. 205 y $206 \mathrm{del}$ Código Civil, todos deducidos por Jueces de Familia; y b) art 10, inc. $2^{\circ}$, de la ley $n^{\circ} 18.216$ (que establece penas sustitutivas a las penas privativas de libertad), $y$ art 17 B de la ley 17.798 (de control de armas), principalmente deducidos por Jueces de Garantía, el Tribunal Oral en lo Penal o las Cortes de Apelaciones. De este breve análisis, es posible deducir que el número de requerimientos a iniciativa del juez o tribunal son escasos, y que, a nuestro juicio, tendría igualmente su origen en la problemática que estamos abordando en el presente artículo.

Ahora bien, en relación al desarrollo científico alcanzado por la dogmática nacional en este tema, se deben poner de relieve las siguientes perspectivas:

1. Se debe partir indicando que es asumido en nuestro medio el carácter concreto de la cuestión de inaplicabilidad ${ }^{5}$ en tanto el objeto del control de constitucionalidad no es solamente el precepto legal sino los efectos de su aplicación. No obstante, la forma escueta y breve que emplea literalmente la normativa constitucional (art. 93, n 6), deja más interrogantes que respuestas acerca del contenido y límite de los elementos de control concreto de la inaplicabilidad así concebida. Más aún si no se definió -ni en el texto de las reformas a la Constitución ni en su génesis- qué será lo que debe entenderse por "control concreto" de constitucionalidad de preceptos legales para efectos de la inaplicabilidad; solamente precisado por la normativa fundamental, como un examen de aplicación del precepto legal con resultado contrario a la Constitución (Pica Flores, 2012, pp.64-65).

Esta configuración de potestades, control concentrado-concreto, deviene necesariamente en la exigencia de definir y delimitar el concepto y elementos del control concreto en el marco que consagra nuestro sistema concentrado,

\footnotetext{
${ }^{5}$ Desde sus inicios así lo ha establecido la doctrina nacional, por todos: Vega Méndez y Zúñiga Urbina (2006).
} 
que, al mismo tiempo, subsisten con la atribución del Poder Judicial de conocer y resolver procesos ejerciendo jurisdicción. Todo ello hace necesario, además, investigar acerca de la delimitación de potestades de la jurisdicción constitucional, en sede de control concreto, con las propias de la jurisdicción común, temática que, como ya lo hemos mencionado, no ha estado exenta de problemas y ambigüedades conceptuales que tensionan la institucionalidad de los órganos jurisdiccionales implicados ${ }^{6}$. En efecto, la reforma constitucional del año 2005, en esta parte, tuvo por idea matriz fortalecer la concentración del modelo de justicia constitucional, eliminando la posibilidad de control difuso de constitucionalidad $y$, al referirse a la inaplicabilidad de un precepto legal de aplicación contraria a la Constitución, trasladó la preeminencia del juicio de constitucionalidad, desde la formulación del texto de la ley hacia el escrutinio de los efectos que produce su aplicación, al sustituirse del antiguo artículo 80 de la actual Carta la frase "precepto legal contrario a la Constitución" proveniente de la anterior Constitución de 1925, por la fórmula "precepto legal cuya aplicación en cualquier gestión que se siga ante un tribunal ordinario o especial, resulte contraria a la Constitución". Este cambio de fórmula ha significado un verdadero empoderamiento en el proceso -radicado originariamente en el tribunal de fondo- por parte del Tribunal Constitucional, pues al verse compelido a ponderar los elementos del mismo y los efectos de la aplicación de la norma, de una u otra forma, está acercándose, o tocando, las potestades que parecen ser propias de los jueces del fondo, abriendo un foco de tensión que no ha sido suficientemente abordado por nuestra doctrina y que ya ha dejado en evidencia un déficit de articulación -y de un modo recíproco- entre Tribunal Constitucional y Tribunales Ordinarios en los casos específicos de sentencias de inaplicabilidad. De ahí que se haya dicho por un autor en nuestro medio, que la introducción del control concreto "implica grados diferentes de conocimiento de los jueces constitucionales acerca del asunto de fondo y, en cierto sentido, de 'invasión' o 'intromisión' en el mismo", lo cual no debiera generar problemas en la medida que el control sea de carácter estricto y no se amplíe en demasía (Gómez Bernales, 2005, pp. 673 y 677).

La doctrina chilena, que en principio fue entusiasta del control concreto, ha sido minoritaria en precisar que en el sistema chileno ya "no sólo el producto de la actividad del legislador estará sujeto a control de constitucionalidad, sino que también las resoluciones de los jueces y magistrados"(Hormazábal Malarée, 2008, p. 18); en la medida que la única forma posible de aplicación de un precepto legal, a un caso concreto pendiente de resolver ante un tribunal ordinario o especial, es la dictación de resoluciones judiciales a su amparo, interpretando el precepto y subsumiendo en él los hechos litigiosos. Para, mediante dichas resoluciones judiciales, producir un determinado resultado que se tra-

${ }^{6}$ Destacado por la doctrina: Mendizábal Allende (2005) y Bordalí Salamanca (2006, p. 45). Rev. derecho (Coquimbo, En línea) 2019, 26: e3589 
duce en resolver la gestión de determinada forma, lo que, si produce un resultado contrario a la Constitución, será declarado inconstitucional de manera preventiva, antes de que ello ocurra, en sede de inaplicabilidad, o bien, si ya se produjo -sin que se encuentre agotada la aplicación del precepto en la gestión invocada-, en ciertos casos la sentencia de inaplicabilidad operará como "amparo imperfecto o cuasi amparo" (Cazor Aliste y Pica Flores, 2009), con la evidente alteración de las potestades del tribunal del fondo de conocer y juzgar la normativa que sustenta los actos procesales y la resolución del asunto ha sido declarada inaplicable. Siendo decisiva en lo que se encuentra pendiente, el juez debe resolver en sentido contrario, alterándose el resultado del proceso por causa de la sentencia de inaplicabilidad, dejándose sin efecto lo resuelto anteriormente por el tribunal del fondo en nombre de la ley -en el caso de cuasi amparo-, debiendo resolverse en nombre de la Constitución, entendida en los términos que se interprete en la sentencia de inaplicabilidad.

2. De igual forma, en la literatura local el tema en estudio (delimitar las esferas jurisdiccionales entre los Tribunales Ordinarios y el Tribunal Constitucional, para los efectos de la acción de inaplicabilidad), no ha sido abordado correcta ni directamente. Por un lado, la tesis de Silva Irarrázabal (2012) parte justamente de la base de relativizar la separación entre legalidad y constitucionalidad (asunto sustancial en nuestra formulación), maximizando la relación entre ambas órbitas competenciales, para plantear que la ley es un elemento de interpretación constitucional, finalmente negando la posibilidad de diferenciar constitucionalidad y legalidad, lo cual, en vez de proponer soluciones al problema, termina negándolo para, en última instancia, no formular propuestas; lo que deja una mayor confusión entre ambas órbitas y es incoherente con la existencia de un Tribunal Constitucional de control concreto. Si ello fuese así, el efecto de cuasi amparo no podría haberse producido jamás, en donde los tribunales podrían hacer control difuso y el Tribunal Constitucional no existiría. Por otro lado, se constata que se ha llegado a los contornos de esta temática (Zuñiga Urbina, 2005 y Fernández González, 2005), más a propósito del recurso de casación y su fundamentación en normas constitucionales, sin salir de ese eje y sin entrar en la delimitación de la órbita competencial de ambas jurisdicciones, para solamente discutir si sería o no un ejercicio de control difuso. Asimismo, los partidarios del control difuso (Martínez Estay, 2005) no abordan el sentido problemático de esta investigación, pues en su tesis no existe límite que fijar entre las atribuciones del Juez Ordinario y del Tribunal Constitucional, en tanto el Juez Ordinario puede inaplicar por sí mismo sin requerir ante este último Tribunal. Finalmente, se encuentra la tesis de Núñez Poblete (2012), el que sostiene que la jurisdicción ordinaria puede desaplicar un precepto legal en ausencia y en presencia de antinomias, en frente de la atribución del Tribunal Constitucional para declarar la inaplicabilidad, inten- 
tando sostener la existencia de competencias concurrentes entre la jurisdicción ordinaria y la constitucional. Vector que es el opuesto de lo que se busca en este trabajo, que apunta a reconocer la existencia de un modelo concentrado que requiere forzosamente establecer y delimitar campos competenciales; en este sentido, las críticas a la tesis de Silva Irrarázabal (2012) son también extrapolables aquí.

En definitiva, la doctrina local expuesta denota una insuficiencia -e incluso una negación- en el tratamiento de la problemática desarrollada en el presente artículo.

\section{Propuestas en torno a la delimitación de las esferas jurisdicciona- les intervinientes, en el contexto de la acción de inaplicabilidad}

Ahora nos toca analizar algunas propuestas en torno al tema en estudio, las que centraremos en los siguientes tópicos:

1. En el caso chileno, el problema se vislumbra en el contexto de su actual modelo de control concentrado de constitucionalidad de la ley, toda vez que se produce una confusión en cuanto al rol de los jueces -tanto constitucionales como ordinarios- al momento de aplicar la Constitución, generando una dualidad de órganos, en principio, con funciones y culturas funcionariales distintas. Así, se ha invocado en varios casos por los jueces ordinarios el artículo $5^{\circ}$, inciso $2^{\circ}$, de la Carta, en relación con el principio de aplicación directa e inmediata de la Constitución -a partir del artículo $6^{\circ}$, inciso $2^{\circ}$, de la misma Norma fundamental-, como sustento para "inaplicar" o desaplicar determinados preceptos legales en casos concretos, sin requerir -como sería lo lógico- el pronunciamiento del Tribunal Constitucional por vía de la acción de inaplicabilidad (Núñez Poblete, 2012b). Esto es lo que algunos autores han denominado como una especie de "control difuso de constitucionalidad" (Ríos Álvarez, 2005), que relativiza la concentración del sistema de justicia constitucional actual y genera problemas desde el punto de vista del diseño institucional de reparto de competencias atributivas y desde el punto de vista de la falta de unidad en la interpretación constitucional (sobre todo cuando está involucrada la temática de los derechos fundamentales). Además, dentro de un sistema jurídico como el chileno, que no tiene una modalidad de precedentes vinculantes que cumpla la función de unificar la jurisprudencia, nos conduce, asimismo, a la problemática de la fuerza vinculante de la sentencia de inaplicabilidad y su exigibilidad, que si bien conceptualmente emanan del efecto de cosa juzgada, carecen de mecanismos de imposición especiales, a falta de una norma que consagre el carácter supremo y obligatorio para todos los poderes 
Delimitación de las esferas jurisdiccionales entre los tribunales ordinarios y el tribunal...

públicos la interpretación que el Tribunal Constitucional haga de la Carta fundamental ${ }^{7}$, normas que pueden considerarse esenciales para el cumplimiento de las finalidades del modelo concentrado y que sí existen en otros sistemas distintos al nuestro (como el caso alemán, español o peruano, entre otros).

2. Se detecta el problema de que, en la medida que la cuestión de inaplicabilidad tenga un mayor grado de concreción, puede llegar a ser el Tribunal Constitucional quien -en la práctica- precisa el resultado del juicio, sin tener potestades para resolver el fondo del asunto ni revisar resoluciones judiciales, lo que implica centrar el examen en la resolución de la gestión invocada, haciéndolo tan estricto que el campo de acción del juez del fondo se reduce considerablemente, lo cual tiene una incidencia "direccionadora" en la resolución de la gestión invocada en el requerimiento, alterando la legislación aplicable y condicionando el resultado del proceso. En efecto, esta anomalía se da cuando la acción de inaplicabilidad puede operar como una especie de "amparo imperfecto"(Cazor Aliste y Pica Flores, 2009 y Cazor Aliste, 2011), ello en razón de la tutela general que ejerce el Tribunal Constitucional sobre los derechos fundamentales, ya que si el requerimiento se promueve en una gestión pendiente relativa a una acción garantizadora de los mismos (protección, hábeas corpus, entre otras) el pronunciamiento del órgano de jurisdicción constitucional será vinculante para el juez ordinario, como asimismo, el razonamiento judicial empleado; lo que evidentemente condicionaría la decisión del mismo, restringiendo sus facultades constitucionales para conocer y resolver conforme al mérito del proceso, al amparo de una norma constitucional que ya fue interpretada para el caso concreto, respecto de un acto recurrido que estaba amparado por la ley declarada inaplicable, en un evidente y sobrevenido cambio de escenario decisivo para el tribunal del fondo.

Igualmente, el Tribunal Constitucional, en reiteradas oportunidades, en que se han promovido inaplicabilidades sobre preceptos legales de naturaleza procesal, para desechar la argumentación del requirente sobre la influencia del vicio de inconstitucionalidad en el caso concreto, ha analizado derechamente la tramitación procesal del juicio o gestión pendiente, estimando que, en caso de que ella no adolezca de defectos de constitucionalidad, la infracción constitucional denunciada carece de relevancia, criterio que ha permitido a la práctica forense utilizar la sede de inaplicabilidad como una especie de tercera instancia o sede alternativa a los recursos de casación y nulidad, lo que pugna abiertamente con el principio de separación de poderes. En paralelo, y aunque parezca contradictorio, las Salas del Tribunal Constitucional han elaborado copiosa jurisprudencia de inadmisibilidad (Navarro Beltrán y Carmona Santander, 2015) tendiente a diferenciar sus potestades y las de los tribunales

\footnotetext{
${ }^{7}$ Esta problemática es de especial relevancia, pues el modelo concentrado chileno reconoce algunas potestades de interpretación que no pueden ser revisadas por el Tribunal Constitucional al Poder Judicial y a la Contraloría General de la República.
} 
del fondo de la gestión, argumentando que se le formulan "cuestiones de mera legalidad", que a su juicio escaparían de la órbita de los conflictos de constitucionalidad, pretendiendo una separación tajante e irrestricta entre legalidad y constitucionalidad, cuestión que, por ejemplo, en materia de derechos fundamentales no resulta posible del todo, atendido el rol y funcionalidad del principio de reserva de ley en tanto garantía normativa de los derechos (Pica Flores, 2013). Todo lo cual, sin un desarrollo argumentativo muy lato, llevaría a una relativización del carácter concreto de la inaplicabilidad, al centrarse en el contraste del campo de la legalidad y el campo de la constitucionalidad, transformándola en una simple abstracción del sistema de fuentes, dejando de lado el examen de los efectos de la aplicación del precepto, declarando contra texto constitucional que ordena examinar los efectos de la aplicaciónque no sería un tema de su competencia, y, al mismo tiempo, dejando de lado el rol del legislador en la configuración y regulación de los derechos fundamentales, que son casi siempre las normas constitucionales invocadas en los requerimientos de inaplicabilidad.

3. Se destaca también el asunto de los efectos de las sentencias del Tribunal Constitucional (Zúñiga Urbina, 2006), sobre todo respecto a su carácter vinculante, particularmente en lo concerniente a su ratio decidendi, en sus interpretaciones de tipo general de normas constitucionales y en relación a los antecedentes de la gestión pendiente en la que incida el pronunciamiento del órgano de jurisdicción constitucional; asimismo, lo tocante al imperio que posee el Tribunal Constitucional para hacer cumplir una sentencia de inaplicabilidad y cómo puede obligar al tribunal ordinario o especial para que acate lo decidido: "En el actual modelo, la última palabra la tienen los tribunales donde está radicada la gestión, lo que puede estimarse como un vacío o deficiencia del modelo" (Gómez Bernales, 2013, pp. 61-62). Un claro ejemplo, es lo que aconteció en el denominado "Caso Gómez Montoya", en donde la Corte Suprema, en sede de protección (Gómez Montoya Mario contra Corporación administrativa del poder judicial, zonal $V$ región, 2011), desestima la declaración de inaplicabilidad ${ }^{8}$, argumentando que el precepto legal ya había sido aplicado y que la inaplicabilidad no era la vía idónea para revisar las consecuencias de situaciones jurídicas ya creadas y consolidadas; cuestión atípica que encontraría su justificación en que, por imperativo de la misma Constitución (art. 76), la facultad de conocer y juzgar la gestión invocada corresponde a los tribunales del fondo. En un sentido diverso, pero con similar temática, el caso Rol 2341-12 del Tribunal Constitucional incidía en un reclamo sobre transparencia (Corte de Apelaciones de Santiago Rol N5232-12), que fue fallado a pesar de

\footnotetext{
8 (Requerimiento de inaplicabilidad por inconstitucionalidad de la Corte de Apelaciones de Valparaíso respecto del artículo 4으 de la Ley № 19. 531, sustituido por el artículo 1o de la Ley № 20.224, en los autos Rol № 300-2010 sobre recurso de protección interpuesto ante la Corte de Apelaciones de Valparaíso en contra de la Corporación Administrativa del Poder J udicial, 2011)
} 
Delimitación de las esferas jurisdiccionales entre los tribunales ordinarios y el tribunal...

la suspensión decretada, lo cual acarreó un recurso de queja (Corte Suprema Rol N 8847-12). Lo que además llama a la necesidad de estudiar la eficacia de las denominadas sentencias atípicas, particularmente las denominadas interpretativas de rechazo (Avilés Hernández, 2010), que desestiman cuestiones de inaplicabilidad por existir una interpretación y una aplicación de la norma acorde con la Constitución: ¿Se encuentra ello fuera de las atribuciones del Tribunal Constitucional, por ser propio de las potestades que la misma Constitución asigna al tribunal del fondo para conocer y juzgar? ¿Qué posición tienen las sentencias interpretativas en el sistema de fuentes y cuál es su poder sobre la judicatura? En este mismo sentido, ricas en interpretaciones y que condicionan lo resuelto, son las sentencias de inaplicabilidad referidas al " $\mathrm{Ca}$ so turno abogados" (Rol N ${ }^{\circ} 755-07$, que declara inaplicable la gratuidad de la institución del turno) y al "Caso definición de matrimonio" (Rol № 1881-10 que se pronunció sobre la constitucionalidad del matrimonio heterosexual actualmente en vigor), constatándose en ambas, que sus directrices de razonamiento y argumentación no fueron seguidas por los jueces del fondo, toda vez que la gratuidad no ha sido compensada hasta la fecha, y los jueces desecharon las interpretaciones del Tribunal Constitucional a propósito del matrimonio, respectivamente. Constatándose muchos casos más con problemáticas similares.

\section{Conclusiones}

1. Se puede plantear que, como primera conclusión, más que la dicotomía entre control concentrado y difuso, hoy es la diferenciación entre control abstracto y control concreto la conceptualización más habitual, particularmente teniendo en cuenta que la introducción del control concreto en un sistema concentrado de jurisdicción constitucional, es el hecho gatillante de la necesidad de delimitar y articular a dicha jurisdicción con el Poder Judicial. Ya que, en la práctica, no existe una separación clara entre las jurisdicciones que operan estrictamente en el ámbito de la Constitución y otras exclusivamente en el ámbito de la ley; de ahí que, sea cual sea el modelo de justicia constitucional que se adopte, y exista o no Tribunal Constitucional, todo juez participa en la función de garantía jurisdiccional de la Constitución, y en este sentido todo juez es -potencialmentetambién juez constitucional.

2. Partiendo de la base que la delimitación de las esferas jurisdiccionales entre los Tribunales Ordinarios y el Tribunal Constitucional no está explícita en el ordenamiento jurídico chileno para los efectos de la acción de inaplicabilidad, resulta necesario distinguir la línea que delimite el control concentrado de inaplicabilidad con las potestades de los jueces ordinarios para aplicar e interpretar la ley de conformidad con la Constitución, a fin de descifrar qué es lo 
que puede hacer el juez ordinario y hasta dónde puede llegar en nombre de la Constitución en su actividad jurisdiccional, determinándose cuándo realmente se van a encontrar limitadas sus potestades, y cuándo surgiría la necesidad de la declaración de inaplicabilidad, recurriendo al Tribunal Constitucional, para poder así actuar a nombre de la Constitución. Por esta razón, resulta esencial reconocer la existencia de un conflicto de constitucionalidad real y no aparente de parte del juez ordinario para poder requerir de inaplicabilidad, y en qué medida el conflicto aparente hace emerger las potestades de interpretación conforme del juez de fondo (cuestión directamente vinculada con la delimitación de las esferas jurisdiccionales de los órganos que les toca resolver el asunto). Todo ello se traducirá en redefinir el rol de los jueces ordinarios aplicando la Constitución en la resolución de un conflicto de legalidad; $y$, asimismo, permitirá delinear el rol del Tribunal Constitucional en esta materia, a fin de precisar el reconocimiento de los conflictos constitucionalidad a los cuales dedicará sentencias definitivas, lo que implicará una mayor concreción del espacio jurisdiccional de este Tribunal en la esfera de la inaplicabilidad, reforzándose los efectos de las sentencias que emita (Zúñiga Urbina, 2006), sobre todo respecto a su carácter vinculante con el juez de fondo.

3. Para precisar la conclusión anterior, sería aparente todo aquel conflicto en el cual el enunciado normativo del precepto legal parece inconstitucional, pero el juez ordinario haciendo una interpretación y aplicación contextualizada del mismo, dotándolo de contenido a la luz de alguna norma o principio constitucional, puede arribar a una solución argumentativa que le permita cumplir, al mismo tiempo, con los dos horizontes de obediencia normativa simultáneas o doble sumisión de los jueces: la Constitución y la ley (Aragón Reyes, 1998,p. 164) en cuyo caso el juez jamás necesitara formular una cuestión de inaplicabilidad, por lo cual ese conflicto no llegará a la órbita de atribuciones competenciales del Tribunal Constitucional (art. $93 \mathrm{n}^{\circ} 6$ de la Carta). Al contrario, sería real el conflicto de constitucionalidad, cuando el resultado inconstitucional derivado de la aplicación de la norma legal, es imposible de evadir por vía interpretativa del precepto legal sin contrariar el texto expreso de la Carta, en cuyo caso la declaración de inaplicabilidad pasa a ser una verdadera necesidad para que se cumpla el estándar exigido por la Constitución en la solución del asunto en concreto.

4. En resumidas cuentas, la determinación de si una cuestión es de constitucionalidad o de mera legalidad es una de las claves en esta materia. Será de legalidad todo aquello que el juez pueda resolver de acuerdo a la Constitución, en uso de los elementos de interpretación lógico y sistemático, eligiendo la opción hermenéutica más acorde con la Constitución. Cuando, a fortiori, esta vía no entregue un resultado hermenéutico acorde con la norma constitucional, surgirá una cuestión de constitucionalidad, al ser necesario impugnar un precepto legal. Esta aparentemente clara frontera no tiene tal carácter en materia 
Delimitación de las esferas jurisdiccionales entre los tribunales ordinarios y el tribunal...

de derechos fundamentales, pues el rol del legislador a este respecto lo hace delimitar, establecer condiciones y supuestos de ejercicio, limitaciones, etc., por lo cual el contenido de tales derechos subjetivos no puede ser evaluado ni determinado prescindiendo de su ley regulatoria.

5. Finalmente, se debe poner de relieve que las dificultades descritas precedentemente, han repercutido también en el escaso número de requerimientos a iniciativa del juez o tribunal, que, a nuestro juicio, podría tener dos causas principales. Por una parte, la dificultad que entraña, en sí, las exigencias de cumplir los requisitos de forma y de fondo para poder deducir esta acción constitucional, lo que trae como consecuencia que los jueces, en su mayoría, optan por ejercer el requerimiento cuando existe una doctrina jurisprudencial consolidada para ser acogidos en definitiva, es decir, el juez de fondo no se arriesga en esta materia y prefiere actuar a sobre seguro (el ejemplo más significativo en la actualidad, son las diversas sentencias que han declarado inaplicable el art $1^{\circ}$, inc. $2^{\circ}$, de la ley $\left.n^{\circ} 18.216\right)$. Por otra parte, al tratarse de un precepto legal que resulta decisivo para resolver el asunto, existe en la práctica una extrema precaución por parte del juez o tribunal de la gestión pendiente, de no generar alguna causal de inhabilidad por el requerimiento de inaplicabilidad, que podría traducirse en que, por su interposición, estaría adelantando su opinión de lo que pretendería sentenciar en definitiva en la causa de fondo, lo que en última instancia inhibiría igualmente el ejercicio de esta acción constitucional.

\section{Referencias Bibliográficas}

Aguilar y Maya, J. (1945). La supremacía constitucional. México, DF: Procuraduría general de la República.

Alejandro Faine Maturana, 5232-2012 (Corte de Apelaciones de Santiago 6 de enero de 2014). Recuperado de https://bit.ly/2Nnsx2l

Alejandro Faine Maturana, 8847-2012 (Corte Suprema de Santiago 28 de noviembre de 2012). Recuperado de https://bit.ly/2PPgU65

Aragón Reyes, M. (1998) Estudios de derecho constitucional. Madrid: Centro de estudios políticos y constitucionales.

Avilés Hernández, V. (2010). Las sentencias interpretativas del tribunal constitucional y los cuestionamientos o dificultades que las mismas representan. Revista de derecho público, (72), 211-225. Recuperado de https://bit.ly/36AYCvd 
Bordalí Salamanca, A. (2006). La tutela de los derechos fundamentales bajo un sistema dual de justicia constitucional. En su Justicia constitucional y derechos fundamentales (pp. 33-68). Santiago: LexisNexis.

Cazor Aliste, K. (2011) Casos paradigmáticos de la acción de inaplicabilidad como amparo imperfecto. En P. Marshall Barberán (Coord.). Jurisprudencia constitucional destacada (pp. 239-250). Análisis crítico. Santiago: Abeledo Perrot-LegalPublishing.

Cazor Aliste, K. (2001) La jurisdicción constitucional en Chile. Revista de derecho (Valdivia), 12(1), 91-106. Recuperado de http://bit.ly/36xKtiq

Cazor Aliste, K. y Pica Flores, R.(2009) Tribunal constitucional y control concreto en Chile: ¿evolución hacia un amparo imperfecto?. Revista general de derecho constitucional, (7), 13-39. Recuperado de https://bit.ly/2NfluaO

Constitución Política de la República de Chile (1980). Ministerio Secretaría General de la Presidencia, Santiago, Chile, 8 de Agosto de 1980. Recuperado de http://bcn.cl/1 uva9

Cruz Villalón, P. (1987). La formación del sistema europeo de control de constitucionalidad (1918-1939). Madrid: Centro de estudios constitucionales.

Díaz Revorio, F. (2009). Tribunal constitucional y procesos constitucionales en España: Algunas reflexiones tras la reforma de la ley orgánica del tribunal constitucional de 2007. Estudios constitucionales, 7(2), 81-108. http://doi.org/10.4067/S071852002009000200004.

Fernández-Fontecha Torres, M. (2011). Derecho constitucional. La centralidad del Parlamento. Madrid: Congreso de los Diputados.

Fernández González, M. (2005). Constitución y casación: ¿De la falta de aplicación al monopolio constitucional?. Estudios constitucionales, 3(1), 97-118. Recuperado de https://bit.ly/2PO5T4X

García de Enterría y Martínez-Carande, E. (1988). La Constitución como norma y el tribunal constitucional. Madrid: Civitas.

Gómez Bernales, G. (2013) Las sentencias del tribunal constitucional y sus efectos sobre la jurisdicción común. Santiago: Ediciones Universidad Diego Portales.

Gómez Bernales, G. (2005) La reforma constitucional a la jurisdicción constitucional. El nuevo tribunal constitucional chileno. En F. Zúñiga Urbina (Coord.). Reforma constitucional (pp. 651-684). Santiago: LexisNexis.

Gómez Montoya Mario contra Corporación administrativa del poder judicial, zonal v región, 4518-2011 (Corte Suprema 24 de mayo de 2011).Recuperado de https://bit.ly/36Exyv0 
Delimitación de las esferas jurisdiccionales entre los tribunales ordinarios y el tribunal...

Hormazábal Malarée, H. (2008) El nuevo tribunal constitucional. Santiago: Legal Publishing.

Martínez Estay, José Ignacio (2005) Recurso de inaplicabilidad, el tribunal constitucional y juez ordinario en la reforma constitucional. En H. Nogueira Alcalá (Coord.). La constitución reformada de 2005 (pp. 457-472). Santiago: Librotecnia.

Mendizábal Allende, R. (2005) La guerra de los jueces: tribunal supremo vs tribunal constitucional. Revista de derecho procesal, (1), 489-536.

Navarro Beltrán, E. y Carmona Santander, C. (Eds.). (2015). Recopilación de jurisprudencia del Tribunal Constitucional (1981-2015) (Vol. 59). Santiago: Tribunal Constitucional. Recuperado de https://bit.ly/2NHF3Zt

Núñez Poblete, M. (2012). Desaplicación e inaplicación jurisdiccional de las leyes en Chile: ejercicio de la jurisdicción y control concreto de constitucionalidad. Revista de derecho (Coquimbo. En línea), 19, (2), 191-236. https://doi.org/10.4067/S071897532012000200007.

Núñez Poblete, M. (2012b) Los efectos de las sentencias en el proceso de inaplicabilidad en Chile: examen a un quinquenio de la reforma constitucional. Estudios constitucionales, 10(1), 15-64. https://doi.org/10.4067/S0718-52002012000100002.

Pegoraro, L. (2004). La justicia constitucional: una perspectiva comparada. (M. León Alonso, Trad.). Madrid: Dykinson.

Pica Flores, R. (2013). Aspectos teóricos y jurisprudenciales en torno a la reserva legal de regulación y limitación en materia de derechos fundamentales. Revista de derecho (Coquimbo. En línea), 20(1), 193-228. https://doi.org/10.4067/S071897532013000100008.

Pica Flores, R. (2012). Control jurisdiccional de constitucionalidad de la ley en Chile. Santiago: Editorial jurídica de Santiago.

Pizzorusso, A. (2007) Los sistemas de justicia constitucional: de los modelos a la praxis. En su: Justicia, Constitución y Pluralismo (2a ed., pp. 117-132). Lima: Palestra.

Pizzorusso, A., Volpe, G., Sorrentino, F. y Moretti, R. (1981). Garanzie costituzionali. Art. 134-139. Bologna: Zanichelli e Roma Società Editrice del Foro Italiano

Rolla, G. (2005). Juicio de legitimidad constitucional y tutela de los derechos fundamentales. Revista iberoamericana de derecho procesal constitucional, (3), 271-291.

Ruiz-Tagle Vial, P. (1999). Control de constitucionalidad concentrado y difuso: El uso de una dicotomía ruinosa. Revista de derecho público, (61), 81-95. Recuperado de https://bit.ly/2PVTR9w 
Ríos Álvarez, L. (2005) Trascendencia de la reforma constitucional en la fisonomía y las atribuciones del tribunal constitucional. Estudios constitucionales, 3(1), 73-95. Recuperado de https://bit.ly/2JVweKK

Rubio Llorente, F. (1997) La forma del poder. Madrid: Centro de estudios políticos y constitucionales.

Requerimiento de inaplicabilidad por inconstitucionalidad presentado por Alejandro Fainé Maturana respecto de inciso cuarto del artículo $8^{\circ}$ de la Ley $N^{\circ} 19.640$, de 1999, orgánica constitucional del Ministerio Público, en los autos sobre reclamo de ilegalidad, caratulados "Faine Maturana Alejandro con Ministerio Público", de que conoce la Corte de Apelaciones de Santiago, 2341-12 (Tribunal Constitucional 14 de agosto de 2013). Recuperado de https://bit.ly/32mMwTc

Requerimiento de inaplicabilidad por inconstitucionalidad presentado por la Corte de Apelaciones de Santiago respecto del artículo 102 del Código Civil, en los autos Rol No 6787-2010, sobre recurso de protección interpuesto ante la Corte de Apelaciones de Santiago en contra de Oficial de Registro Civil Adjunto, 1881-10 (Tribunal Constitucional 27 de diciembre 2010). Recuperado de https://bit.ly/2CgCW9F

Requerimiento de inaplicabilidad por inconstitucionalidad de la Corte de Apelaciones de Valparaíso respecto del artículo $4^{\circ}$ de la Ley № 19.531, sustituido por el artículo $1^{\circ}$ de la Ley № 20.224, en los autos Rol № 300-2010 sobre recurso de protección interpuesto ante la Corte de Apelaciones de Valparaíso en contra de la Corporación Administrativa del Poder Judicial, 1801-10 (Tribunal Constitucional 12 de abril de 2011). Recuperado de https://bit.ly/2pD4qnw

Requerimiento de inaplicabilidad por inconstitucionalidad presentado por Sergio Toloza Rodríguez y el Presidente del Colegio de Abogados de Chile respecto del artículo 595 del Código Orgánico de Tribunales, en los autos sobre apelación de protección, caratulados "Sergio Toloza Rodríguez con Juez de Familia de Osorno", de que conoce la Corte Suprema, 755-07 (Tribunal Constitucional 22 de marzo de 2007). Recuperado de https://bit.ly/2NnH5PA

Silva Irrarázabal, L. (2012) ¿Es el tribunal constitucional el supremo intérprete de la constitución?. Revista de derecho (Valparaíso), (38), 573-616. https://doi.org/10.4067/S0718-68512012000100014.

Tomás y Valiente, F. (1993) Escritos sobre y desde el tribunal constitucional. Madrid: Centro de estudios constitucionales.

Vega Méndez, F. y Zúñiga Urbina, F. (2006) El nuevo recurso de inaplicabilidad por inconstitucionalidad ante el tribunal constitucional. Teoría y práctica. Estudios Constitucionales, 4(2),135-174. Recuperado de https://bit.ly/34yaCfe 
Delimitación de las esferas jurisdiccionales entre los tribunales ordinarios y el tribunal...

Weber, A. (1986). La jurisdicción constitucional en Europa occidental: una comparación. Revista española de derecho constitucional, 6(17), 47-84. Recuperado de https://bit.ly/2pMMAhH

Zúñiga Urbina, F. (2006). Control de constitucionalidad y sentencia, Santiago: Tribunal constitucional. Recuperado de https://bit.ly/2qrPFng

Zúñiga Urbina, F. (2005). Control de constitucionalidad y casación. Estudios constitucionales, 3(2), 15-27.

Zúñiga Urbina, F. (2002). Elementos de jurisdicción constitucional (Vol. 1), Santiago: Universidad Central de Chile.

\section{Para citar este artículo bajo Norma APA 6a ed.}

Cazor Aliste, K y Pica Flores, R. (2019). Delimitación de las esferas jurisdiccionales entre los tribunales ordinarios y el tribunal constitucional. Revista de Derecho (Coquimbo. En línea), 26, e3839. https://doi.org/10.22199/issn.0718-9753-2019-0010 